\title{
¿Lucha contra la criminalidad mediante el cumplimiento íntegro y efectivo de las penas?
}

\author{
Carmen López Peregrín iD \\ Profesora Titular de Derecho penal, Universidad Pablo de Olavide de Sevilla
}

\section{RESUMEN}

La Ley Orgánica 7/2003, de 30 de junio, de medidas de reforma para el cumplimiento íntegro y efectivo de las penas, ha introducido importantes modificaciones relativas a la pena de prisión en el Código penal español que afectan, sobre todo, al límite máximo de cumplimiento efectivo de la pena de prisión en casos de acumulación de penas por varios delitos y a las condiciones para acceder al tercer grado y a la libertad condicional. En este comentario se exponen y analizan críticamente los términos de la reforma.

\section{ABSTRACT}

The 7/2003 Bill of June 30 introduces measures to guarantee "truth-in-sentencing" in the Spanish context. This Bill includes important changes in the regulation of custodial sentences in the Spanish Criminal Code, particularly when defining the maximum length in the case of multiple charges and when defining the criteria for access to parole and the low-security, more flexible and less punitive correctional regimes. This essay describes and criticizes the terms of this reform.

\section{Introducción}

La Ley Orgánica 7/2003, de 30 de junio, de medidas de reforma para el cumplimiento íntegro $\mathrm{y}$ efectivo de las penas, ha introducido importantes modificaciones relativas a la pena de prisión en un Código penal, como el español, que apenas tiene siete años de vigencia.

En la Exposición de Motivos de la citada ley se menciona, como argumento que supuestamente justifica esta reforma, en primer lugar, la seguridad jurídica. En concreto, "el derecho del ciudadano a conocer con certeza cuál es la forma en la que se van a aplicar las penas, a saber, en definitiva, en qué se va a traducir en la práctica la pena o sanción impuesta", disminuyendo los "amplios ámbitos de discrecionalidad" que existen en este campo. En segundo lugar, se alega también como justificación de esta ley que las modificaciones introducidas tienen como objetivo "una lucha más efectiva contra la criminalidad" y una "protección más eficaz frente a las formas de delincuencia más graves", como los delitos de terrorismo o los procedentes del crimen organizado.

Si esta reforma es adecuada o no para lograr dichas finalidades es, sin embargo, más que discutible. Y, aunque fuera adecuada, tampoco estaría exenta de dudas la constitucionalidad de los medios empleados.

Por mi parte, tengo que adelantar ya en este momento que mi valoración de la Ley Orgánica 7/2003 es negativa. Al final de este comentario expondré algunas de las razones que me llevan a ello. Pero antes, y con la finalidad de que el lector pueda formarse por sí mismo una opinión al respecto, describiré brevemente cuál era la situación antes de la reforma e intentaré explicar lo más claramente posible (lo cual no resulta en absoluto fácil, dada la complejidad técnica del tema) cuáles han sido los

Revista Española de Investigación Criminólogica

REIC AC-02-03 http://www.criminologia.net

ISSN 1696-9219

https://doi.org/10.46381/reic.v1i0.6 
cambios introducidos. También mencionaré la Ley Orgánica 11/2003, de 29 de septiembre, de medidas concretas en materia de seguridad ciudadana, violencia doméstica e integración social de los extranjeros (ya en vigor) y el Proyecto de Ley Orgánica por la que se modifica la Ley Orgánica 10/1995, de 23 de noviembre, del Código penal (actualmente -octubre de 2003- en tramitación parlamentaria), aunque respecto a ellos sólo me ocuparé de las modificaciones al Código penal que están relacionadas con las cuestiones que aquí se analizan.

De lo que se trata, en el fondo, es de intentar entre todos reflexionar pausada y razonadamente sobre el sentido que tienen las penas, sobre las finalidades que éstas tienen que cumplir y sobre los límites del Estado en su imposición.

\section{La situación anterior a la Ley Orgánica 7/2003}

Tras la entrada en vigor de la Constitución, se hacía necesario iniciar un proceso codificador que desembocara en la aprobación de un nuevo Código penal que se adaptara a la nueva situación jurídica, esto es, la creación de un texto legal que, con el máximo consenso posible, estableciera los presupuestos y los límites de la imposición de penas en un Estado social y democrático de Derecho, dando lugar a lo que después se daría en llamar "el Código penal de la democracia".

Entre otros principios fundamentales que la nueva norma debía respetar, la Constitución española había establecido en su artículo 25,2 que "las penas privativas de libertad y las medidas de seguridad estarán orientadas hacia la reeducación y reinserción social". Sin embargo, en el momento en que se produjo el proceso codificador (un largo periodo que abarcó desde 1978 a 1995, en que se aprobó el Código penal) ya no estaba tan claro ni qué había de entenderse por "reeducación" o "reinserción social", ni cómo debía plasmarse esta "orientación" en el sistema de penas.

Lejos quedaban ya, desde luego, los tiempos en los que reinaba el optimismo resocializador, en los que se confiaba en el efecto beneficioso que podía tener la prisión para el delincuente en el sentido de conseguir, mediante su reeducación, que no volviera a cometer delitos tras su puesta en libertad. Las penas en general, y sobre todo la pena de prisión, no pueden garantizar la no reincidencia del condenado. Aún imaginándonos un sistema penitenciario absolutamente perfecto, con prisiones que tuvieran todos los medios posibles, materiales y humanos (lo cual dista mucho de la realidad carcelaria: interesantes datos ofrece al respecto Cid Moliné, 2002), el mundo al que se devuelve a quien ha estado preso es imperfecto y las razones por las que se delinque (o, desde perspectivas más actuales, por las que se califica o convierte a alguien en delincuente) son muchas, variadas y complejas.

En el momento de elaboración del nuevo Código penal, como decía, resultaban ya evidentes las grandes limitaciones y las múltiples contradicciones de la idea de resocialización del delincuente. Se le criticaba, por ejemplo, su propia fundamentación teórica (en el sentido de que sigue centrando el problema en el delincuente, al que hay que reeducar, y no en la sociedad que produce la delincuencia) o las dificultades de su puesta en práctica en prisión: ¿cómo puede pretenderse la educación para la libertad en condiciones de no libertad, en un ambiente separado de la sociedad que se rige por sus propias pautas de comportamiento, calificado de subcultura carcelaria? (sobre las deficiencias de la idea de resocialización ya Muñoz Conde, 1980, y García-Pablos de Molina, 1984). Pero el caballo de batalla de los críticos de la resocialización ha sido siempre su falta de eficacia, aludiéndose a las altas cuotas de reincidencia de quienes habían cumplido penas de prisión (el "nada da resultado" de Martinson en 1974, 
refiriéndose a la ineficacia del tratamiento del delincuente para evitar la nueva comisión de delitos, ha tenido grandes repercusiones hasta nuestros días).

Todo ello, unido al reconocimiento de la realidad de las prisiones y a la falta de medios (que coincide con la crisis del Estado social), determinó la sustitución del utópico ideal de la resocialización por el más modesto, pero más realista y funcional, de la no desocialización del penado en prisión (Hassemer y Muñoz Conde, 1989, p. 159). En otras palabras, de lo que se trataba era de idear un sistema de sanciones penales que, partiendo de que la prisión no sólo no garantiza la reincidencia, sino que incluso a veces la fomenta, tendiera a minimizar sus efectos negativos sobre el penado.

A grandes rasgos, éste era el contexto en el que se desarrolló el proceso codificador que dio lugar a la aprobación del Código penal de 1995 (la desconfianza hacia la resocialización no haría después más que aumentar, como veremos, y a ello no son ajenos los acontecimientos del 11-septiembre). En este sentido, la redacción del nuevo Código penal pretendía esencialmente (unas veces con mejor y otras veces con peor fortuna) conjugar, de un lado, la necesidad de mantener la pena de prisión y, de otro, la conveniencia de evitar en lo posible la desocialización del condenado. En lo que ahora nos interesa, el entendimiento del papel (limitado, pero necesario) que debía cumplir la idea de resocialización en la pena de prisión se plasmó en el Código penal de 1995, y en la legislación penitenciaria que lo desarrolla, a través de tres decisiones de gran trascendencia en la concepción del sistema de penas (sobre todo esto, véase Muñoz Conde y García Arán, 2002, pp. 527-530):

\section{a) El límite mínimo de la pena de prisión}

Respecto al límite mínimo de la pena de prisión, se prescindía de las penas de prisión excesivamente cortas. En efecto, se entendió que una pena de prisión corta (de tres meses, por ejemplo) no ofrecía tiempo suficiente para ningún tipo de tratamiento siquiera tendente a la reeducación y producía un gran efecto desocializador (pérdida del empleo, problemas familiares, etc.). En estos supuestos, y teniendo en cuenta que se trataba de delitos de poca gravedad, lo más conveniente para evitar la desocialización que produciría el internamiento en un centro penitenciario era prescindir de las penas de prisión inferiores a seis meses y recurrir en esos casos a penas alternativas, como el arresto de fin de semana o la multa.

Este aspecto no ha resultado afectado por la reforma que aquí se comenta, aunque el Proyecto de modificación del Código penal actualmente en tramitación prevé rebajar este límite mínimo de la pena de prisión a tres meses y suprimir la pena de arresto de fin de semana.

\section{b) El límite máximo de la pena de prisión}

Respecto al límite máximo de la pena de prisión, el legislador de 1995 partía de la idea de que había que renunciar a las penas de prisión excesivamente largas por ser inhumanas y desocializadoras, pues suponen en la práctica la separación definitiva del individuo respecto a la sociedad.

Así, se establecía un marco penal para cada delito, en función de la gravedad de éste, que no podía superar en relación a la pena de prisión, como regla general, el tope máximo de veinte años (salvo lo que excepcionalmente establecieran otros preceptos; así, por ejemplo, en casos de muerte de una persona causada por miembro de banda armada, organización o grupo terrorista la pena de prisión puede alcanzar los treinta años).

Revista Española de Investigación Criminólogica

REIC AC-02-03 http://www.criminologia.net

ISSN 1696-9219 
En el caso de que se cometieran varios delitos en relación de concurso real (varias conductas dan lugar a varios delitos), en principio se imponen al sujeto todas las penas correspondientes a todos los delitos cometidos para su cumplimiento simultáneo (por ejemplo, prisión y multa) o, si éste no es posible, sucesivo (por ejemplo, dos penas de prisión). Sin embargo, el cumplimiento de todas las penas impuestas (sentido original del término cumplimiento íntegro) es a veces simplemente imposible, por ejemplo, cuando las suma de las penas de prisión impuestas (un total de 60, 80, 300, 500 años...) excede de las expectativas de vida del condenado; y otras veces puede dar lugar a internamientos a perpetuidad o a penas de prisión excesivamente largas.

Para evitar estos inconvenientes, y sobre todo para hacer compatible el fin retributivo de la pena (penas proporcionales a la gravedad de los delitos cometidos) con la posibilidad de resocialización del delincuente, se preveían unos topes para este tipo de supuestos de acumulación de penas. Según estos topes, el máximo de cumplimiento efectivo de prisión no podía exceder del triple de la pena más grave de las impuestas ni de veinte (regla general), veinticinco o treinta años (en casos excepcionalmente graves). En otras palabras, por muchos y muy graves que fueran los delitos cometidos, el cumplimiento efectivo de la pena de prisión no podía exceder (y ello en supuestos excepcionales) de treinta años (rige, pues, en nuestro ordenamiento el principio de acumulación material limitado por el principio de acumulación jurídica). Esto es algo que nunca resulta bien explicado en los medios de comunicación, en donde es corriente encontrar noticias en las que se informa $(i ?)$, por ejemplo, de que un condenado a 150 años de prisión sólo ha cumplido 20 ó 30, en un tono habitualmente dirigido (de forma consciente o no) a crear una sensación de inseguridad y de desconfianza hacia el sistema penal mayor del que éste merece. En efecto, por muy graves que fueran los delitos cometidos (10 asesinatos, castigados cada uno de ellos con 18 años de prisión, por ejemplo), el Código penal entendía, en la línea ya indicada, que el cumplimiento de una pena de prisión de más de 30 años impediría por completo el fin resocializador y de reinserción social que debía tener la pena.

Este límite ha sido, sin embargo, modificado (aumentado) por la Ley Orgánica 7/2003, como veremos seguidamente.

\section{c) El sistema de individualización científica}

Por último, además de fijar los límites máximo y mínimo de la pena de prisión y el máximo de cumplimiento efectivo, era necesario también tomar decisiones respecto a la forma en que había de cumplirse la pena de prisión impuesta. En este sentido, se aceptaba en nuestro ordenamiento un sistema de individualización científica aplicable a todos los condenados a penas de prisión, sin distinción alguna en base al delito cometido.

Según este sistema, la pena de prisión establecida por el juez en la sentencia puede cumplirse en diferentes regímenes, que abarcan desde un internamiento cerrado muy estricto, con muy escasos contactos con el exterior, hasta la libertad condicional, lo que habrá de decidirse en función de las circunstancias del caso concreto. En efecto, una vez que el condenado entra en el establecimiento penitenciario lo importante no es ya la gravedad de la conducta realizada (o no sólo): el interno es clasificado para su destino al establecimiento penitenciario más adecuado en función de la personalidad y el historial individual, familiar, social y delictivo del interno, la duración de la pena impuesta, el medio al que retornará y las facilidades o dificultades para el buen éxito del tratamiento.

En función de estos criterios, desde el primer momento el condenado es clasificado en primer grado (máxima seguridad), segundo grado (régimen normal, con posibilidad 
de obtener por ejemplo permisos de salida de hasta 36 días al año) o tercer grado (régimen abierto, que permite por ejemplo que el interno realice actividades laborales fuera del centro debiendo sólo permanecer en éste para pernoctar de lunes a viernes). A lo largo de su estancia en prisión, la calificación puede variar atendiendo a la conducta y a la evolución (positiva o negativa) del preso.

Una vez en tercer grado, el sujeto puede obtener la libertad condicional cuando ha cumplido una parte de la pena de prisión (tres cuartas partes o, excepcionalmente, dos tercios -los únicos supuestos en los que el Código penal permite la concesión de la libertad condicional sin que se hayan cumplido estos plazos son los casos de sentenciados mayores de 70 años o enfermos muy graves con padecimientos incurables, art. $92 \mathrm{Cp}$-). Ello supone cumplir el último tramo de la pena en libertad (aunque pueden imponérsele ciertas reglas de conducta de obligado cumplimiento), pero con la condición de no volver a cometer ningún delito pues, si lo hiciera, tendría que volver a ingresar en prisión para cumplir el resto de pena que le quedase (además de la que se le impusiera por el nuevo delito cometido).

Para situar al lector, a 30 de junio de 2001 (datos de la Dirección General de Instituciones Penitenciarias recogidos por Cid Moliné, 2002, pp. 20 y 25), del total de condenados clasificados en grados (hay un porcentaje a la espera de clasificación) el $2{ }^{\prime} 8 \%$ se encontraba en primer grado, el $82{ }^{\prime} 2 \%$ en segundo grado y el $15 \%$ en tercer grado. Por su parte, el número de libertades condicionales concedidas en 2001 por cada 100 condenados/as era inferior a 14 (aunque el porcentaje se ha visto reducido a la mitad en el periodo 1996-2001). El pequeño porcentaje de los clasificados en primer grado confirma la excepcionalidad del régimen cerrado, previsto sólo para quienes presentan una gran peligrosidad o son considerados inadaptados a los regímenes ordinario o abierto. La clasificación de terroristas en primer grado es, por lo demás, habitual. En el otro extremo, es también relativamente pequeño el porcentaje de clasificados en tercer grado. Y ello aunque el Reglamento Penitenciario de 1996 modificó la situación anterior permitiendo la clasificación en tercer grado desde el primer momento, cuando las circunstancias del reo así lo aconsejaran (era el caso, por ejemplo, de algunos condenados por insumisión, cuando aún estaba tipificada como delito, o de algunas personas condenadas a penas cortas que hubieran ingresado por primera vez en prisión).

El régimen de semilibertad que supone el tercer grado conlleva, lógicamente, la necesidad de analizar detenidamente las circunstancias concretas del reo antes de concederlo y, en este sentido, la clasificación inicial en este grado, siendo posible, resultaba en la práctica relativamente excepcional. La inmensa mayoría de los condenados son clasificados inicialmente en segundo grado. Así, la evolución normal, si el sujeto no es considerado peligroso, tiene buena conducta y participa en las actividades reeducadoras, es comenzar en segundo grado, pasar con el tiempo a tercer grado y cumplir el último tramo de la pena en libertad condicional. Sin embargo, el sistema de individualización científica permite también la regresión en grado o la revocación de la libertad condicional en casos de evolución negativa del penado.

Con este sistema de cumplimiento se pretendía una adaptación progresiva del condenado a la vida en libertad. En este sentido, la progresión a tercer grado y a la libertad condicional supone la concesión de un más amplio espacio de libertad que se decide una vez analizado el caso concreto cuando se tiene una cierta garantía de éxito en el uso de ese margen de confianza y una perspectiva razonable de no utilización indebida del mismo en relación a la comisión de nuevos delitos o al quebrantamiento de la condena (Sentencia de la Audiencia Provincial de Cantabria de 5 de abril de 2000). $\mathrm{Y}$, a pesar de las deficiencias del sistema, la experiencia parece haber confirmado que 
partir de un sistema de individualización científica no es un planteamiento erróneo, pues (aunque resulta difícil medir la eficacia de estas medidas por la multitud de variables que determinan la reincidencia o no del penado) algunas estadísticas indican que quienes han sido puestos en libertad bruscamente, tras un internamiento en prisión, cometen más delitos que quienes disfrutaron de una puesta en libertad progresiva (Cid Moliné, 2002, p. 22).

En el momento de la redacción del Código penal de 1995, y sobre todo de la legislación penitenciaria, se entendió, pues, que la clasificación del condenado en primer, segundo o tercer grado y la concesión o no de la libertad condicional eran decisiones que debían adoptarse en atención a las características individuales del sujeto en cada momento. Lo que entonces se consideró flexibilidad para ofrecer la mejor solución al caso concreto, consecuencia necesaria del fin resocializador de la pena (o de lo poco que había quedado de él), se califica sin embargo hoy, como puede verse en la Exposición de Motivos de la Ley Orgánica 7/2003, como un amplio margen de discrecionalidad a combatir $(\dot{i}$ ?).

El sistema implantado por el Código penal de 1995 no era, sin embargo, perfecto. Muchas han sido las críticas que se le han dirigido. Y con razón. Así, por ejemplo, se le criticó que supuso en realidad un endurecimiento de las penas. Ello tiene varios motivos, pero quizá el principal consiste en que el nuevo Código suprimía la figura de la redención de penas por el trabajo (que en la práctica suponía una reducción de un tercio de la condena), sin que se rebajaran los marcos penales previstos de forma equivalente. Así, aunque el anterior Código y el nuevo tuvieran prevista la misma pena para un determinado delito (6 años de prisión, por ejemplo), resultaba más beneficioso para el reo el sistema anterior, pues aplicando la redención de penas por el trabajo la pena quedaba reducida a 4 años. En otras palabras, 6 años del nuevo Código penal son más años de prisión que 6 del anterior.

Que el sistema de penas del nuevo Código resulta más duro que el anterior puede constatarse con cifras (Cid Moliné, 2002, pp. 15 y 16), pues si bien en el periodo 19962001 disminuyeron los ingresos en prisión (lo cual no significa necesariamente reducción de la delincuencia), aumentó el número de presos, lo que indica una permanencia más larga en prisión de los condenados (pueden verse estadísticas en la página web de la Dirección General de Instituciones Penitenciarias). España tiene, de hecho, una de las mayores (la tercera) cifras de encarcelamiento de la Unión Europea. En ello influye seguramente también el escaso uso que el Código penal hace de las penas alternativas a la prisión, abusando, por tanto, del recurso a esta última pena.

También se ha criticado mucho en los últimos años el desarrollo penitenciario del Código penal y en concreto (a pesar de los grandes avances producidos) las grandes deficiencias que aún presentan las prisiones y las consiguientes dificultades para perseguir fines rehabilitadores por la escasez de medios.

Pero claro, como pone de manifiesto la sabiduría popular, "otro vendrá que bueno me hará”. Y ha venido la reforma de la Ley Orgánica 7/2003.

\section{Medidas introducidas por la Ley Orgánica 7/2003}

Lo que hace la reforma introducida por esta ley es, de un lado, aumentar el límite máximo de cumplimiento efectivo de la pena de prisión y, de otro, modificar el régimen de individualización científica de la pena. La intención es que los condenados por determinados delitos, considerados especialmente graves, permanezcan más tiempo en prisión y en condiciones más gravosas. Sin embargo, como veremos más adelante, 
aunque la reforma se dirige especialmente contra la criminalidad grave, en algunos aspectos afecta a un ámbito mucho más amplio de delitos (véase infra, lo referente al periodo de seguridad).

En concreto, las novedades son, básicamente:

a) Elevación del límite máximo de cumplimiento efectivo de la pena de prisión (art. 76 Código penal)

Como ya se ha dicho, el Código penal establecía antes de la reforma que el máximo de cumplimiento efectivo de la pena de prisión cuando se han cometido varios delitos era, en los casos más graves, de 30 años. Ahora ese tope se amplía a 40 años, lo que supone en muchos casos prácticamente instaurar la cadena perpetua.

Este máximo de 40 años se aplica cuando el sujeto haya sido condenado por dos o más delitos y, al menos, dos de ellos tengan prevista en la ley una pena superior a 20 años de prisión (por ejemplo dos asesinatos cualificados, como sería matar con alevosía y ensañamiento) o cuando haya sido condenado por dos o más delitos de terrorismo, estando al menos uno de ellos castigado con pena de prisión superior a 20 años.

\section{b) Endurecimiento de las condiciones para la obtención del tercer grado}

La legislación penitenciaria admitía la posibilidad, como hemos visto, de calificar en tercer grado desde el primer momento a un condenado a la pena de prisión en virtud de sus circunstancias personales, permitiéndole así pasar directamente (exceptuando el tiempo necesario para realizar el estudio de su personalidad) al régimen de semilibertad sin necesidad de pasar por los anteriores.

La reforma establece, por el contrario, el llamado "periodo de seguridad" (art. 36.2 Código penal), de manera que, cuando se ha impuesto una pena de prisión superior a cinco años, se impide la concesión del tercer grado penitenciario hasta no haber cumplido la mitad de la pena impuesta. Supongamos, por ejemplo, que un sujeto con problemas de autocontrol ha sido condenado a ocho años de prisión por un delito de lesiones. Pues bien, el periodo de seguridad impediría, en principio, al condenado acceder al régimen de semilibertad hasta haber cumplido cuatro años de prisión, y ello aunque se hubiera sometido voluntariamente a un programa de tratamiento que hubiera conseguido excelentes resultados en relación al control de su agresividad y hubiera un pronóstico de peligrosidad cero. Existe, sin embargo, una excepción: el juez de vigilancia puede, valorando las circunstancias del reo y la evolución del tratamiento, aplicar el régimen normal de cumplimiento (pudiendo por tanto acceder al tercer grado antes de cumplir la mitad de la pena), salvo que se trate de delitos de terrorismo o cometidos en el seno de organizaciones criminales (por ejemplo, delitos vinculados al narcotráfico).

Lo que antes era la regla general (acceso al tercer grado sin necesidad de haber cumplido una parte determinada de la condena) se convierte ahora en excepción si la pena de prisión es superior a cinco años (excepción no aplicable, por lo demás, a todos los condenados). En estos supuestos se cierra además, en la práctica, la posibilidad de clasificación inicial en tercer grado, ya que el régimen excepcional exige que el juez de vigilancia tenga en cuenta la evolución del tratamiento reeducador, que, por consiguiente, ha debido de estar en marcha durante un tiempo relevante como para poder apreciar resultados.

La obtención del tercer grado requiere ahora, además, la satisfacción de la responsabilidad civil, teniendo en cuenta a estos efectos, entre otras circunstancias, la 
conducta reparatoria observada por el condenado, sus condiciones personales y patrimoniales, a efectos de valorar su capacidad real, presente y futura, para satisfacer la responsabilidad civil y las garantías que permitan asegurar su satisfacción futura. Por otro lado, si se trata de delitos de terrorismo o cometidos en el seno de organizaciones criminales es requisito también el haber colaborado con las autoridades y mostrar "signos inequívocos" de haber abandonado los fines y los medios de la actividad terrorista, lo que puede acreditarse "mediante una declaración expresa de repudio de sus actividades delictivas" y "una petición expresa de perdón a las víctimas" (arts. 72.5 y 6 Ley Orgánica General Penitenciaria, introducidos también por la Ley Orgánica 7/2003).

En otras palabras y con un ejemplo, para que un sujeto de 30 años de edad condenado a 40 años de prisión por dos delitos de terrorismo pueda acceder al tercer grado deberá haber cumplido 20 años de prisión (la mitad de la pena impuesta, y ya hemos visto que el periodo de seguridad no admite excepciones en supuestos de terrorismo) $\mathrm{y}$, además, haber pagado la responsabilidad civil (que en delitos de terrorismo puede ser muy elevada) o garantizar su pago con sus bienes presentes (itras 20 años de cárcel?) o futuros (¿podrá a sus 50 años ya obtener bienes suficientes para ello?) y haber colaborado con las autoridades en la persecución de los delitos cometidos en el seno de la organización a la que pertenecía (¿qué información podrá dar tras 15 ó 20 años de reclusión?).

Pero eso no es todo. En determinados supuestos se hace aún (i!) más difícil la concesión del tercer grado. Explicaré a qué casos me refiero.

Tanto antes como después de la reforma, cuando un sujeto ha cometido varios delitos ha de cumplir en principio todas las penas que correspondan, aunque, como hemos visto, se establecen ciertos límites: así, la pena a cumplir efectivamente no puede exceder del triple de la más grave de las impuestas (por ejemplo, si un sujeto ha sido condenado a 1 año de prisión por cada uno de los 5 hurtos cometidos y a dos penas de 2 años cada una por sendos robos, el total a cumplir no puede ser superior a 6 años -el triple de 2-, aunque la suma total sea 9). Y, en cualquier caso, la pena a cumplir efectivamente no puede ser superior, según los supuestos -art.76-, a 20, 25, 30 ó -a partir de la entrada en vigor de la Ley Orgánica 7/2003- 40 años de prisión.

En estos supuestos, el régimen general de cumplimiento establece que los plazos para el acceso al tercer grado (la mitad de la pena impuesta en los casos de aplicación del periodo de seguridad) se computen en relación, no a la suma total de las penas impuestas, sino al máximo de cumplimiento efectivo según los topes legales (en el ejemplo, para acceder al tercer grado tendrá que haber cumplido tres años de prisión -la mitad de 6, tope legal; no la mitad de 9, suma total de las penas impuestas-).

La existencia de límites máximos de cumplimiento efectivo de la pena de prisión puede dar lugar, sin embargo, a que la pena a cumplir sea muy inferior a la suma total de las impuestas, lo cual ha sido considerado razón suficiente por el legislador del 2003 para establecer un régimen más duro de acceso al tercer grado en algunos de estos supuestos. Así, el art. 78 establece ahora que, en los casos de acumulación de penas por varios delitos, cuando a consecuencia de los límites de cumplimiento efectivo de la prisión la pena a cumplir es inferior a la mitad de la suma de las impuestas, el juez o tribunal puede acordar que el cómputo de los plazos para la obtención del tercer grado se refiera, no al tope máximo que puede cumplir efectivamente, sino a la totalidad de las penas impuestas en la sentencia.

Aclaremos este trabalenguas con un ejemplo. Supongamos que un sujeto ha cometido siete robos, castigado cada uno con 4 años de prisión. Estamos en el caso previsto en el art. 78, pues el máximo de cumplimiento efectivo de la pena de prisión a aplicar en este supuesto (el triple de 4, es decir, 12 años) es inferior a la mitad de la 
suma total de las penas impuestas ( 7 robos por 4 años de prisión=28 años de prisión). En este supuesto, el juez puede establecer en la sentencia que el cómputo para el tercer grado (la mitad) se refiera, no al máximo de pena a cumplir (12), que sería lo normal, sino a la suma total (28), luego en este caso no podría acceder al tercer grado hasta cumplir 14 años de prisión (la mitad de 28). O sea, que, si el juez hace uso de la posibilidad que le otorga el art. 78 , el sujeto no podría acceder al tercer grado pues saldría en libertad definitiva (a los 12 años) antes de cumplir el tiempo de cumplimiento que sería necesario (14 años) para acceder a dicho grado. Esto es siempre así, pues si estamos en un supuesto en el que el tiempo de pena a cumplir (máximo de cumplimiento efectivo) es inferior a la mitad de la suma total de las penas impuestas, la mitad de esta última cifra siempre será superior a aquélla (matemática pura).

Este régimen, previsto como opcional para cualquier caso en que la pena a cumplir efectivamente resulte inferior a la mitad de la suma total de las impuestas, se convierte en obligatorio (el juez o tribunal sentenciador debe acordarlo en la sentencia) cuando, además, alguno de los delitos por los que ha sido condenado el culpable tenga prevista una pena de prisión de hasta 20 años o más.

Así, por ejemplo, si un sujeto es condenado por cuatro asesinatos cualificados a 22 años de prisión cada uno, la pena máxima a cumplir (en este caso, 40 años) es inferior a la mitad del total de penas impuestas $(4 \times 22=88$ años). En este supuesto el juez o tribunal sentenciador debe acordar en la sentencia que el cómputo de los plazos para el tercer grado (la mitad) se refiera, no al máximo de cumplimiento efectivo (40), sino al total de penas impuestas (88), por lo que en este caso no podrá acceder al tercer grado, pues saldrá en libertad definitiva a los 40 años (máximo legal) sin haber cumplido el plazo para acceder al tercer grado (la mitad de 88 es 44 años).

Existe en ambos casos, sin embargo, la posibilidad excepcional de que en un momento posterior, en atención a la evolución del condenado, el juez de vigilancia penitenciaria decida aplicarle el régimen normal (es decir, cómputo respecto del máximo legal de cumplimiento efectivo: la mitad de 12, en el primer ejemplo; la mitad de 40, en el segundo). Pero si se trata de delitos de terrorismo o cometidos en el seno de organizaciones criminales, sólo se permite otorgar el tercer grado cuando quede por cumplir una quinta parte del tope máximo de cumplimiento (suponiendo que un terrorista hubiera sido condenado por tres muertes a 30 años de prisión cada una, sólo podría acceder al tercer grado cuando le quede por cumplir un quinto de 40 -máximo legal-: se le permitiría - y ello sólo en casos excepcionales, de pronóstico favorable de reinserción social y evolución positiva del tratamiento, además de los requisitos anteriormente vistos de garantía de cumplimiento de la responsabilidad civil, colaboración con las autoridades y signos inequívocos de abandono de la actividad terrorista- acceder al tercer grado cuando ya ha cumplido ¡32 años de prisión!).

La posibilidad de tener en cuenta la suma total de las penas impuestas para el cómputo de los plazos fue ya introducida por el Código penal de 1995, pero sólo en relación con los beneficios penitenciarios y la libertad condicional. Como veremos después, la Ley 7/2003 no sólo mantiene y endurece este régimen respecto a la libertad condicional (a pesar de las muchas críticas que recibió cuando se introdujo en 1995, véase, por ejemplo, Requejo Conde, 2000, p. 558), sino que lo extiende a la concesión del tercer grado y de permisos de salida.

\section{c) Restricciones a la libertad condicional}

El régimen para la obtención de la libertad condicional también se ha visto modificado (arts. 90, 91 y 93 Código penal). Antes de la reforma eran requisitos para la 
libertad condicional estar en tercer grado penitenciario, haber cumplido ya tres cuartas partes (o excepcionalmente dos tercios) de la condena y tener buena conducta y un pronóstico favorable de reinserción social. Si el condenado volvía a delinquir en el periodo de libertad condicional o infringía las reglas de conducta que se le hubieran impuesto, se revocaba la libertad condicional y debía cumplir en prisión lo que le quedaba de pena, descontando el tiempo que hubiera estado en libertad condicional.

La reforma introducida por la Ley Orgánica 7/2003 añade un nuevo requisito para la obtención de la libertad condicional (haber satisfecho la responsabilidad civil, en los términos ya vistos, lo que de todas formas es necesario para la obtención del tercer grado, paso previo a la libertad condicional) e introduce tres modificaciones esenciales en los supuestos de condenados por delitos de terrorismo o cometidos en el seno de organizaciones criminales. En estos casos:

1. para que haya un pronóstico favorable de reinserción social es preciso que el sujeto haya colaborado con las autoridades y "muestre signos inequívocos" de haber abandonado la actividad terrorista, lo que puede acreditarse "mediante una declaración expresa de repudio de sus actividades delictivas" y "una petición expresa de perdón a las víctimas" (lo cual, como hemos visto, es también requisito necesario para obtener el tercer grado en este tipo de delitos).

2. no es aplicable el régimen excepcional de libertad condicional, en el que basta haber cumplido dos tercios de la condena (o incluso menos: art. 91.1 y 2).

3. si se revoca la libertad condicional, al condenado no se le descuenta del resto de la pena que tenga que cumplir en prisión el tiempo que estuvo en libertad condicional (sólo para los condenados por delitos de terrorismo).

Además de estas modificaciones del régimen de la libertad condicional, y al igual que ocurría respecto al tercer grado, el art. 78 establece ahora que, en casos de condena por varios delitos, si los topes máximos de cumplimiento efectivo conducen a establecer una pena a cumplir inferior a la mitad de la suma de las impuestas el juez o tribunal sentenciador puede acordar que los plazos para la libertad condicional se refieran a la totalidad de las penas impuestas en la sentencia, y debe hacerlo (y ésta es la novedad introducida por la Ley Orgánica 7/2003 en este ámbito) cuando alguno de los delitos por los que ha sido condenado el sujeto tiene prevista en la ley una pena de hasta 20 años de prisión o superior. En el caso del condenado por cuatro asesinatos cualificados a 22 años de prisión cada uno, éste debería cumplir 3/4 de 88 años, es decir, 66 años de prisión, para poder obtener la libertad condicional, aunque sabemos que sólo puede cumplir efectivamente 40 .

Aquí también se prevé que, excepcionalmente y en un momento posterior, el juez de vigilancia penitenciaria, en atención a la evolución del penado, decida aplicarle el régimen general. Pero si se trata de condenados por delitos de terrorismo o cometidos en el seno de organizaciones criminales, sólo es posible conceder la libertad condicional (excepcionalmente) cuando le quede por cumplir una octava parte del límite máximo de cumplimiento ( $1 / 8$ de 40 , en nuestro ejemplo, 35 años de prisión ya cumplidos).

Se dificulta, pues, en gran medida la obtención de la libertad condicional en este tipo de supuestos. En cualquier caso, al ser el tercer grado requisito para la obtención de la libertad condicional esta previsión se vuelve a menudo superflua, pues si se le impide prácticamente acceder a aquélla, nunca podrá optar a ésta.

\section{d) Entrada en vigor}

La Ley 7/2003 entró en vigor al día siguiente al de su publicación en el Boletín Oficial del Estado, es decir, el 2 de julio. 
En la Disposición transitoria única de dicha ley se establece expresamente, además, que lo dispuesto en ella respecto a las circunstancias para acceder a la libertad condicional y al tercer grado será aplicable a todas las decisiones que se adopten después de esa fecha con independencia del momento de comisión de los hechos delictivos o de la fecha de la resolución en virtud de la cual se esté cumpliendo la pena. En mi opinión ello plantea dudas de constitucionalidad por contradicción con el principio de irretroactividad de las leyes penales desfavorables para el reo (a favor de su constitucionalidad, sin embargo, el Informe del Consejo General del Poder Judicial, 2003, pp. 38-39, aunque introduciendo algunos matices al tenor literal de la ley).

\section{Las "razones" de la reforma}

La Ley Orgánica 7/2003 es criticable, desde mi punto de vista, por muchas y diversas razones. La propia denominación de la ley induce ya a confusión, pues hace referencia a "medidas para el cumplimiento íntegro y efectivo de las penas" cuando en realidad se refiere al incremento del máximo de cumplimiento efectivo en casos de acumulación de penas (que sigue sin poder ser íntegro en casos, por ejemplo, de condenas a una suma total de 150 años de prisión) y al endurecimiento -e incluso imposibilidad- de acceder a modalidades de cumplimiento de la pena de prisión (tercer grado, libertad condicional) que no implican permanencia continua en el centro penitenciario. También desde el punto de vista formal son criticables algunas de sus previsiones, como por ejemplo la decisión de incluir en el Código penal la regulación del periodo de seguridad para el acceso al tercer grado, norma que, por estar referida a la ejecución de la pena, debería haberse incluido en la legislación penitenciaria. No haberlo llevado a cabo así ha conducido, de hecho, a la existencia de contradicciones entre esta medida y las previsiones contenidas en la Ley Orgánica General Penitenciaria y en el Reglamento penitenciario (véase el Informe del Consejo General del Poder Judicial, 2003, pp. 2021). Pero, a pesar de existir otras razones para criticar la ley desde el punto de vista formal, en este momento me interesa más centrarme en consideraciones de fondo.

Como puede verse tras el análisis de las modificaciones introducidas por la Ley Orgánica $7 / 2003$, se pretende con la reforma endurecer desde la propia ley las condiciones de cumplimiento de la pena de prisión para los autores de varios delitos castigados con penas de prisión elevadas (aunque ya hemos visto que alguna modificación, como la introducción del periodo de seguridad, afecta a un número mayor de supuestos), limitando de paso la discrecionalidad de los jueces en la toma de decisiones en materia de ejecución penitenciaria $\mathrm{y}$, por tanto, el sistema de individualización científica. Resulta especialmente llamativa la excepcional dureza con la que la ley trata a los responsables de delitos de terrorismo o cometidos en el seno de organizaciones criminales. Ello supone una plasmación más del auge que a nivel internacional está teniendo en los últimos tiempos (aún más tras el 11-septiembre) la idea de retribución, en el peor de los sentidos (de castigo por el castigo), y de inocuización del delincuente en prisión, frente a otras finalidades que debe cumplir la pena, como la resocialización (con todas sus limitaciones).

En efecto, en otros países (como EEUU), fracasadas las esperanzas resocializadoras, se han revalorizado tanto el fin retributivo de la pena (lo que se ha dado en llamar neoretribucionismo) como la función de custodia y control, de neutralización, que cumple la prisión (inocuización), sobre todo respecto a delincuentes peligrosos proclives a la reincidencia. Se tiende así cada vez más a considerar la ejecución de la pena de prisión como un fín en sí mismo, dejando el tiempo de internamiento vacío de contenido rehabilitador y convirtiendo la prisión en "almacenes" de delincuentes, 
internados en ellos cuanto más tiempo mejor, con la finalidad de evitar que cometan delitos en el exterior (curiosamente, cuando se habla de reincidencia suele hacerse referencia exclusivamente a los delitos cometidos por el preso tras su puesta en libertad: a nadie importan los delitos que un condenado pueda cometer contra otro durante su estancia en prisión).

Respecto al neoretribucionismo, está suponiendo en la práctica (aunque no tendría que ser necesariamente así, véase por ejemplo von Hirsch, 1998) a nivel internacional un aumento de las penas previstas para los delitos y un consiguiente aumento de la población carcelaria (un resumen de las plasmaciones del neoretribucionismo en el ordenamiento norteamericano, con instituciones como los "sentencing guidelines", el "minimun mandatory sentences" o el "truth in sentencing" ofrece Larrauri, 1998). Frente a la sensación de inseguridad del ciudadano (a veces fundada, y a veces -las más- creada artificialmente o al menos amplificada interesadamente desde la política y los medios de comunicación), se pretende ofrecer como solución el endurecimiento de la sanción penal. Se transmite la idea (velada o abiertamente) de que cuántos más años de pena de prisión se cumplan y con más dureza (neoretribucionismo e inocuización parecen ir de la mano), mejor se combatirá la criminalidad. Esa premisa no ha sido sin embargo demostrada nunca empíricamente. La experiencia diaria parece más bien confirmar lo contrario, esto es, que al endurecimiento de las penas y al incremento del recurso a la pena de prisión en los últimos años no ha correspondido una disminución del nivel de criminalidad (algunos estudios criminológicos hablan de un "efecto disuasorio moderado" derivado de la certeza y severidad de las penas, aunque referido más a la certeza que a la severidad; por otro lado, algunas investigaciones empíricas parecen demostrar que la existencia de la pena de muerte -la pena más severa- no sólo no reduce la tasa de homicidios, sino que incluso puede producir un efecto brutalizador que hace que ésta aumente; véanse las referencias a estos estudios en Barberet, 1997, pp. 125-128).

De hecho, el límite máximo de pena vigente en el anterior Código penal para casos de acumulación de penas (30 años) había sido ya criticado desde la doctrina por excesivo. Así, por ejemplo, consideraba Cid Moliné (1994, p. 293) que el principio de efectividad -según el cual una sanción penal sólo está justificada si la violencia que evita es superior a la que causa y si, además, se verifica que entre dos sanciones que producen semejante evitación de la violencia, se prefiere la que menor violencia supone- resultaba vulnerado por el límite de 30 años (vigente también en el Código franquista). Y ello porque, en su opinión, resulta muy difícil argumentar que una vez superados 10 ó como máximo 15 años de prisión, los excesos de condena puedan incrementar su capacidad preventiva. "Desde mi punto de vista -dice este autor- los individuos cuyos comportamientos no resulten intimidados por condenas de tal entidad, tampoco lo son por condenas mayores". Al margen de que penas de prisión de 30 años o superiores tienen un nulo efecto resocializador.

El nuevo Código penal, de 1995, mantuvo el límite máximo de la prisión en 30 años para los casos de acumulación de penas. Sin embargo, hay que tener en cuenta que, como ya hemos dicho, el anterior Código preveía la redención de penas por el trabajo, lo que suponía en la práctica la reducción de aproximadamente un tercio de la condena. Con lo que el nuevo Código penal, al suprimir esta figura, supuso ya un grave endurecimiento de las penas previstas en él, que no se rebajaron de manera equivalente. $\mathrm{Y}$ en concreto, aunque formalmente mantenía la cifra máxima de 30 años, en la práctica ese tope resultaba aumentado. No parece haber seguido a ese aumento de la gravedad de las penas una disminución del nivel de criminalidad (ni siquiera ha pasado el tiempo 
suficiente para constatar los efectos del nuevo Código penal) y sin embargo vuelven a endurecerse las penas.

Y si en general no puede afirmarse que un aumento de las penas previstas para un delito (o para el caso de comisión de varios) tenga como consecuencia un descenso de la delincuencia, en relación en concreto a los delitos de terrorismo, o a cualquier otro delito subsumible en lo que se denomina delincuencia por convicción, mucho menos. Pensemos en el caso español. Personalmente estoy convencida de que el aumento del límite máximo de cumplimiento efectivo a 40 años no incidirá en lo más mínimo en la decisión de quien planee una serie de asesinatos terroristas. Ni siquiera la perspectiva de que esos 40 años se tengan que cumplir efectivamente y sin acceso al tercer grado ni a la libertad condicional. Como mucho, puede darse el efecto contrario, pues el trato diferenciado (más gravoso) al terrorismo puede ser usado por el entorno terrorista como un argumento más de la necesidad de la "lucha armada".

Porque lo que me parece realmente grave de la reforma es su insistencia en diferenciar entre dos clases de delincuentes: basta releer el apartado que describe las modificaciones introducidas por la nueva ley y observar cuántas veces se establecen excepciones al régimen general para delitos de terrorismo o cometidos en el seno de organizaciones criminales. Se olvida que el establecimiento de reglas diferentes para un determinado tipo de delincuentes supone una infracción del principio de igualdad. Parece plasmarse así lo que se ha dado en llamar un "Derecho penal del enemigo", un Derecho penal que trata a determinados delincuentes no como ciudadanos que han infringido una norma penal y deben ser castigados como una pena, sino "como enemigos, como meras fuentes de peligro que deben ser neutralizadas del modo que sea, cueste lo que cueste" (Cancio Meliá, 2002, p. 20). Al enemigo se le imponen gravísimas penas y se le recortan garantías del Estado de Derecho, abriéndose con ello "una puerta por la que puede colarse sin darnos cuenta un derecho penal de cuño autoritario" (Muñoz Conde, 2003a).

La admisión de un Derecho penal del enemigo, que distinga entre delincuentes con derechos y delincuentes enemigos del Estado (no-personas, ha llegado a denominarlos Jakobs, 1999, pp. 139-140), con menos derechos (o ninguno?) es, en efecto, altamente preocupante. De presente, supone ya la vulneración de garantías inherentes al Estado de Derecho. De futuro, preocupa pensar quién determinará quién es el enemigo, cómo se establecerán límites al recorte a los derechos de éste y cómo se va a poder evitar que las limitaciones de derechos no se extiendan a la generalidad. ¿O tendremos que asumir, como dijo una jueza norteamericana en su argumentación para prohibir una manifestación en Nueva York contra la guerra de Irak el 15 de febrero de 2003, que las libertades ya no son las mismas tras el 11-septiembre?

En resumen, como ponen de manifiesto Hassemer y Muñoz Conde (2001, pp. 354355), el peligro del neoretribucionismo es que la necesidad de pena no esté realmente vinculada a la idea de proporcionalidad a la gravedad del delito cometido, sino que exprese en realidad un sentimiento de venganza que conduzca a penas desproporcionadas o contrarias a la dignidad humana (como la pena de muerte) más propias de una prevención general puramente intimidatoria que convierta al Estado en un Estado terrorista que, con penas draconianas y un Derecho penal ad hoc pensado especialmente para los enemigos, pretenda acabar con la criminalidad más preocupante haciendo tabla rasa con los derechos humanos y las garantías del Estado de Derecho en aras de un sentimiento irracional de Justicia.

Por otro lado, al neoretribucionismo se añade a nivel internacional el auge de la idea de la inocuización. Curiosamente, la inocuización y la resocialización proceden de un mismo origen. Habitualmente suele atribuirse a Von Liszt (1882) la formulación de 
ambos conceptos. En efecto, este autor sostuvo que el fin que debían cumplir las penas no era el castigo por el castigo, la realización de la justicia (retribución), sino la consecución de la no reincidencia del condenado (prevención especial). Para lograr este fin podían seguirse tres vías diferentes, según las características de cada sujeto. Así, distinguía entre delincuentes corregibles (a los que había que corregir), delincuentes ocasionales (a los que había que intimidar para persuadirles de la comisión de futuros delitos) y delincuentes habituales incorregibles (a los que había que separar de la sociedad). En el desarrollo de su teoría sobre el tratamiento de sujetos corregibles tiene su origen la idea de resocialización. En el desarrollo de su teoría frente a los delincuentes habituales incorregibles, el de la inocuización.

Ya hemos visto, sin embargo, las múltiples críticas de que ha sido objeto la idea de resocialización. Pues ahora hay que añadir que el terreno perdido por el pensamiento resocializador ha ido siendo conquistado por los defensores de la inocuización: si "nada da resultado", si el tratamiento resocializador no garantiza la no reincidencia, entonces (éste parece ser el razonamiento imperante) todos los condenados son incorregibles: limitémonos entonces a inocuizar al delincuente, a separarlo de la sociedad pues al menos el tiempo en el que esté en prisión no podrá delinquir. Destinemos los medios económicos no a mejorar los programas de tratamiento, sino a construir más y mayores prisiones. Y llenémoslas.

En efecto, parece que en los últimos tiempos se ha revalorizado la función de custodia y control, de inocuización, que cumple la prisión, sobre todo con delincuentes peligrosos proclives a la reincidencia. En el fondo, ésta era también la filosofía subyacente en el Proyecto de ley de extraños a la comunidad, que determinaba el internamiento de asociales en los campos de concentración nazis... (véase Muñoz Conde, 2003b).

De forma no tan brutal (aún; aunque ¿qué está ocurriendo en Guantánamo?), en EEUU domina hoy la teoría de la incapacitation, que defiende la función puramente custodial de la prisión para determinado tipo de delincuentes con un pronóstico de peligrosidad criminal (basado normalmente en la reincidencia) durante el tiempo de la prisión, que puede ser indefinido. A esta idea responden las teorías penitenciarias que proponen una "selective incapacitation", como prolongación indefinida de la pena privativa de libertad para delincuentes habituales con pronóstico desfavorable de resocialización, propuesta que se ha concretado ya por ejemplo en algunos Estados de EEUU en los que se permite la retención adicional por tiempo indeterminado del delincuente sexual violento peligroso que ha cumplido ya la pena impuesta (vuelve a ponerse así, de manifiesto, la cercanía de las consecuencias a que conducen inocuización y neoretribucionismo). Por su parte, la Ley alemana para la lucha contra los delitos sexuales (Gesetz zur Bekämpfung von Sexualdelikten und andere gefährlichen Straftaten), de 26 de enero de 1998, maximiza también la idea de seguridad (aunque, a diferencia del modelo americano, no abandona la dimensión resocializadora del tratamiento), permitiendo imponer custodia de seguridad (Sicherungsverwahrung: medida posterior a la pena no limitada por el principio de culpabilidad, introducida por cierto en 1933 por el régimen nazi) desde la primera condena y sin límite temporal si hay riesgo de violencia (sobre todo esto, véase Silva Sánchez, 2001, pp. 700 y ss.).

Estos excesos (y otros) demuestran lo peligroso de la idea de la inocuización. No sólo se olvida la reinserción a la que debe (obligatoriamente en nuestro ordenamiento) tender la ejecución de la pena de prisión, sino que está conduciendo ya en estos países a la introducción de medidas que infringen los principios de legalidad, proporcionalidad y culpabilidad, pilares fundamentales del Derecho penal en un Estado de Derecho. 
En España no se ha llegado (aún) a estos extremos. Pero el auge de la inocuización está llegando y ha quedado plasmado ya en la reforma en tanto en cuanto se le resta operatividad al sistema de individualización científica (cuando no se elimina) limitando el acceso al tercer grado y la libertad condicional y convirtiendo en muchos casos la pena de prisión en un tiempo vacío de contenido rehabilitador (no comparte esta opinión crítica, por ejemplo, Manzanares Samaniego, 2003, p. 206).

Tanto el razonamiento inocuizador en sí como las consecuencias a las que conduce son criticables. Es cierto que el pensamiento resocializador merece críticas, que tiene limitaciones. Pero no es cierto que nada dé resultado. Y tampoco parece muy sostenible una argumentación que, partiendo de la ineficacia de la prisión, en vez de llegar a la conclusión (como sería razonable) de la necesidad de incrementar (cuando sea posible) el uso de penas alternativas, desemboque por el contrario en una tendencia a aumentar, en número de supuestos y en duración de la pena, el recurso a las penas de prisión (según estadísticas de la Dirección General de Instituciones Penitenciarias en España se ha pasado de 33.035 presos en 1990 a 53.937 en 2003).

Respecto a la eficacia o ineficacia del tratamiento resocializador, un equipo de investigadores españoles (véase Redondo, 1997) ha realizado recientemente un estudio sobre 57 programas de tratamiento aplicado a jóvenes y adultos en seis países europeos, en el que se constató una ganancia global favorable de un $15 \%$ de mejora en las puntuaciones de los sujetos tratados frente a los no tratados (referido a todo tipo de logros, académicos, laborables, psicológicos...) y una reducción promedio de la delincuencia en un $12 \%$ (suele partirse internacionalmente de una reincidencia promedio del $50 \%$, por lo que en grupos tratados rondaría el 40\%). La propia implantación de programas de tratamiento influyó positivamente, además, en el funcionamiento de las instituciones en los que se aplicó mejorando el clima y disminuyendo la violencia.

Naturalmente que podría argumentarse que la reducción en 10 ó 12 puntos de la reincidencia no es un resultado muy alentador. Pero es un resultado. Mucho más de lo que ha logrado el pensamiento retributivo, que nunca ha demostrado la más mínima eficacia en la reducción de la delincuencia de un incremento y/o endurecimiento de las penas.

Por otro lado, la afirmación de Redondo en relación a los efectos positivos de la implantación de programas de tratamiento en el funcionamiento de los centros me parece muy importante. Si al condenado se le oferta un tratamiento y si a la evolución positiva frente al tratamiento le sigue la obtención de ciertas ventajas (progresión en grado, libertad condicional), tendremos una oportunidad, aunque no sea muy grande, de resocializar (o al menos no desocializar) al preso en un ambiente, además, más o menos pacífico. El sistema de individualización científica es, junto al tratamiento, fundamental en este sentido (como ya he dicho antes, algunas estadísticas parecen demostrar que quienes siguen un sistema de individualización científica reinciden mucho menos que aquéllos que recuperan bruscamente la libertad, Cid Moliné, 2002, p. 22, García Arán, 2003).

Naturalmente que el sistema premial (que vincula a la evolución del penado el acortamiento de la estancia en prisión y/o la mejora de las condiciones de vida en ella) no está exento de críticas (véase por ejemplo Cid Moliné, 1994, p. 295). Pero, ¿cuál es la alternativa? Si por el contrario se interna a un sujeto en prisión y lo que se le trasmite es que, haga lo que haga, evolucione positiva o negativamente, cumplirá el mismo número de años en prisión y en el mismo régimen, no se me ocurre ninguna razón que le motive a controlar su comportamiento. En casos extremos como los que hemos visto, de práctica prisión perpetua, no sé qué habría de detener a un preso para no matar a su compañero de celda.

La Exposición de Motivos de la Ley Orgánica 7/2003 establece en su apartado II que "la flexibilidad en el cumplimiento de las penas y los beneficios penitenciarios tienen su 
razón de ser en el fin de reinserción y reeducación del delincuente constitucionalmente consagrado, pero, precisamente por ello, la legislación debe evitar que se conviertan en meros instrumentos al servicio de los terroristas y los más graves delincuentes para lograr un fin bien distinto". No puedo estar más de acuerdo con el planteamiento: naturalmente que el tercer grado y la libertad condicional, al permitir un mayor margen de libertad al condenado, deben concederse cuando, como decíamos antes, haya una cierta garantía de éxito en la utilización de ese margen de confianza. A eso se dirige, precisamente, el sistema de individualización científica, pues en él se trata de tomar decisiones individuales en función de las circunstancias concretas de cada caso. Por ello no estoy de acuerdo con la consecuencia que en la Ley se extrae de ese planteamiento, en sí correcto, pues el riesgo de instrumentalización o de fracaso en supuestos aislados debe conducir sólo a la necesidad de perfeccionar el sistema de individualización científica, y no, como hace la Ley, a excluir de este sistema a quienes hayan cometido determinados delitos (a favor de la prisión perpetua se manifiesta sin embargo, por ejemplo, Manzanares Samaniego, 2003, pp. 208211).

En relación, en concreto, con la pena privativa de libertad, hay que tener en cuenta, además, de una parte, que reducir la función de la prisión a la simple custodia de las personas se opone a los conceptos de humanidad y proporcionalidad y, de otra, que la creación fáctica de un sistema de ejecución de penas privativas de libertad exige, por lo menos, una teoría sobre el sentido que debe darse al tiempo que el recluso debe estar en prisión (Hassemer, 1984, p. 354).

En resumen, el aumento sistemático de las penas y el endurecimiento de las condiciones de cumplimiento no parece pues un buen camino para la lucha contra la criminalidad grave. Ni siquiera políticamente parece una opción adecuada: como dice Muñoz Conde, si ni en los años más duros del franquismo se llegó a proponer el cumplimiento efectivo de penas de prisión de 40 años de duración, no se entiende muy bien por qué en un momento en que el problema del terrorismo no es más amenazante que en otras épocas se propone una reforma mucho más severa, rayando -dice este autor- la introducción de la cadena perpetua, que más bien puede tener un efecto contraproducente para una deseable política de reinserción social de los terroristas (Muñoz Conde, 2003a).

En realidad, el sistema introducido por la Ley 7/2003 no es que "raye" la introducción de la cadena perpetua, es que permite la imposición de penas en condiciones más severas que en aquellos países de nuestro entorno donde existe esta pena. En efecto, como pone de manifiesto Téllez Aguilera (2003, pp. 6-7), en países como Italia, Alemania o Francia, que prevén en sus normas penales la pena de cadena perpetua, ésta no se identifica con un internamiento en prisión de por vida sin posibilidad de recuperar la libertad, sino que se puede acceder a la libertad condicional una vez alcanzado un determinado tiempo de cumplimiento (por ejemplo 26 años en Italia o 15 en Alemania). De hecho, los Tribunales Constitucionales de estos países y el propio Tribunal Europeo de Derechos Humanos han manifestado que la admisibilidad de penas de prisión perpetua o de larga duración depende de que exista la posibilidad de una libertad anticipada (véase la jurisprudencia recogida por Téllez Aguilera, 2003, p. 7). En otras palabras, estamos de nuevo ante un fraude de etiquetas porque, sin mencionar el término "cadena perpetua", se ha introducido la posibilidad de cumplir penas en condiciones más gravosas (por ejemplo, un terrorista condenado por varios delitos de gravedad sólo podría -y esto excepcionalmente- acceder al tercer grado tras 32 años de internamiento en prisión y obtener la libertad condicional tras 35) que en aquellos países de nuestro entorno en que se admite (en los términos en los que cabe admitirla en pleno siglo XXI) la pena de cadena perpetua. 
Por otro lado, la introducción de los requisitos de satisfacción de la responsabilidad civil y colaboración con las autoridades impedirá en la práctica (en los escasos supuestos en que quepa) el acceso al tercer grado y la concesión de la libertad condicional, pues, de un lado, las indemnizaciones son en muchos casos imposibles de pagar o garantizar $\mathrm{y}$, de otro, poca colaboración puede darse a las autoridades tras diez o veinte años de permanencia en prisión. El principio constitucional de orientación de las penas a la reinserción social resulta así claramente vulnerado. Porque es cierto que el Tribunal Constitucional ha establecido ya en diferentes ocasiones (véanse, por ejemplo, STC 2/1987, de 21 de enero, y Autos 486/1985 y 1112/1988) que la referencia a la resocialización que realiza el art. 25.2 $\mathrm{CE}$ es una declaración meramente orientativa, que de ella no se deriva un derecho subjetivo para el individuo ni mucho menos un derecho fundamental susceptible de amparo y que no es el único fin al que ha de tender la pena. Pero ello no significa que pueda obviarse por completo el fin resocializador para determinados grupos de delincuentes, como hace la Ley Orgánica 7/2003, al margen de que la previsión de penas tan largas en condiciones tan gravosas de cumplimiento puede resultar contraria a la prohibición constitucional de penas inhumanas y degradantes (art. 15 CE).

El propio Consejo General del Poder Judicial (2003), en su informe del Anteproyecto de la Ley Orgánica 7/2003, al analizar la posible inconstitucionalidad del aumento del límite máximo de cumplimiento efectivo en casos de acumulación de penas hasta 40 años, estableció que esta medida no era incompatible per se con la prohibición contenida en el art. 15 CE ni con la orientación a la resocialización de las penas (2003, pp. 8-11), siempre que, por el modo de cumplimiento (beneficios penitenciarios, modalidades de tratamiento, etc.), no se esté impidiendo de forma significativa la reinserción social del condenado. "Pues, a estos efectos, no es relevante la duración de la pena impuesta si el penado conserva la esperanza de poder ser liberado, aunque sea después de mucho tiempo, en caso de pronóstico favorable de reinserción" (2003, p. 10). Y esa esperanza queda, desde luego, muy debilitada -casi inexistente- para los autores de determinados delitos (sobre todo delitos de terrorismo y cometidos en el seno de organizaciones criminales) tras la reforma. El Consejo proponía, de hecho, en su Informe (p. 22) que se admitiera incluso en delitos de terrorismo o cometidos en el seno de organizaciones criminales la aplicación del régimen general de cumplimiento (cálculo de los periodos mínimos para beneficios penitenciarios, permisos de salida, acceso al tercer grado y libertad condicional referidos a los topes máximos de cumplimiento) cuando existiera un pronóstico favorable de reinserción social. La actual situación legal, que permite sólo -y en casos muy excepcionales- acceder a estos delincuentes al tercer grado cumplidas cuatro quintas partes del máximo legal y a la libertad condicional cumplidas siete octavas partes de la misma no parecen garantizar, en mi opinión, la orientación a la resocialización constitucionalmente establecida.

Pero esta reforma es sólo el principio. En la Ley Orgánica 11/2003, de 29 de septiembre, de medidas concretas en materia de seguridad ciudadana, violencia doméstica e integración social de los extranjeros, se incluyen también modificaciones al Código penal que no me parecen acertadas. Entre ellas, la posibilidad de imponer la pena superior en grado en determinados supuestos de reincidencia (lo que aumenta aún más las dudas de constitucionalidad de esta agravante, por suponer infracción del principio ne bis in idem) y la conversión en delito (con la consiguiente imposición de una pena mayor) de la cuarta falta de lesiones, hurto o hurto de uso de vehículo de motor en un año. En otras palabras, si la Ley Orgánica 7/2003 se dirigía esencialmente (aunque no sólo) a endurecer las condiciones para los delincuentes responsables de varios delitos graves, la Ley Orgánica 11/2003 se dirige contra los reincidentes en general, y en especial contra los pequeños delincuentes. En este momento (octubre 
2003) se encuentra en fase de tramitación parlamentaria, además, un Proyecto de modificación de más de 173 artículos del Código penal en la misma línea de aumento de la represión que, además de introducir nuevos delitos, hace disminuir el límite mínimo de la pena de prisión a tres meses y suprime la pena de arresto de fin de semana.

Esta evolución (imparable?) me merece una opinión muy negativa. La eliminación de la delincuencia es imposible: sólo es posible reducirla a unos límites soportables para la convivencia. La cuestión es, entonces, como ponen de manifiesto Hassemer y Muñoz Conde (2001, p. 221), "cómo se puede conseguir esa reducción o contención de la criminalidad, indispensable para una convivencia pacífica organizada, a unos niveles aceptables, manteniendo unos espacios de libertad que también son indispensables para el desarrollo individual". Y en ese sentido resulta fundamental no permitir que las nuevas tendencias en relación a la pena acaben con las garantías básicas del Estado de Derecho. Por eso me parece necesario partir de la idea de la pena como retribución (pues en la medida en que se asuma la naturaleza de "mal" de la pena, como respuesta al delito cometido, podrá recurrirse a la proporcionalidad como límite de aquélla) e intentar después encontrar un equilibrio entre las necesidades resocializadoras y de defensa de la sociedad, pero dejando claro en todo caso que hay que supeditar la eficacia en la prevención del delito a los principios normativos del Estado de Derecho.

El Derecho penal debería estar limitado, sobre todo, por la idea de humanización (basada en la concepción de la pena como un mal, en la idea de tratamiento como derecho del delincuente y en la necesidad de perfeccionar el sistema de penas) y por el concepto de Derecho penal mínimo, que frene las pretensiones ampliatorias de mecanismos preventivogenerales (Díez Ripollés, 1997, p. 12). En concreto, y por lo que se refiere a los temas aquí tratados, concuerdo totalmente con Cid Moliné (2002, p. 15), quien resumía de una forma muy clara los tres aspectos que deberían configurar "un ideal razonable por lo que hace al papel de la prisión en el sistema punitivo":

a) "usar la prisión sólo en aquellos casos en que no sea posible imponer un castigo más humano -prisión como ultima ratio- y limitar su duración de acuerdo a estándares de humanidad (limitación del uso de la prisión);

b) hacer que las condiciones de vida en prisión se acerquen lo más posible a las de las personas en libertad (normalización de la vida en prisión);

c) posibilitar que durante la ejecución de la pena de prisión la persona pueda participar en programas de tratamiento que puedan dar lugar a su liberación -parcial o totalanticipada (rehabilitación en prisión)."

No es ésta, sin embargo, la línea seguida por la reforma ni la tendencia general. Por el contrario, "la «globalización del modelo económico» está provocando una reducción del Estado social y un aumento del Estado policial, penal y penitenciario" (Hassemer y Muñoz Conde, 2001, p. 335). Y eso es intolerable. 


\section{BIBLIOGRAFÍA}

Barberet, Rosemary (1997), La prevención general y especial, en Varios, La Criminología aplicada, Cuadernos de Derecho Judicial, Consejo General del Poder Judicial, Madrid, pp. 117-147.

Cancio Meliá, Manuel (2002), "Derecho penal" del enemigo y delitos de terrorismo. Algunas consideraciones sobre la regulación de las infracciones en materia de terrorismo en el Código penal español después de la LO 7/2000, Jueces para la Democracia 44, pp. 19-26.

Cid Moliné, José (1994), ¿Pena justa o pena útil? (El debate contemporáneo en la doctrina penal española, Ministerio de Justicia, Madrid.

Cid Moliné, José (2002), El sistema penitenciario en España, Jueces para la Democracia 45, pp. 15-27.

Consejo General del Poder Judicial (2003), Informe sobre el Anteproyecto de Ley Orgánica de medidas de reforma para el cumplimiento íntegro y efectivo de las penas,

http://www.poderjudicial.es/CGPJ/Docuteca/ficheros.asp?intcodigo=1488\&IdDoc $=\mathrm{S}$ $\underline{\mathrm{P}}$

Cuerda Riezu, Antonio (1997), El rotundo fracaso legislativo del llamado «cumplimiento efectivo» de las penas y otros aspectos del concurso de delitos, La Ley 4204, de 10 de enero, pp. 1-4.

Díez Ripollés, José Luis (1997), El bien jurídico protegido en el Derecho penal garantista, Jueces para la Democracia 30, pp. 10-19.

Dirección General de Instituciones Penitenciarias (2003), publica datos estadísticos en http://www.mir.es/oatpp/index.htm

García Arán, Mercedes (2003), Castigo o reinserción eficaz, artículo de prensa publicado en El Periódico de 7 de enero. Puede obtenerse también en http://www.sppu.com/hemeroteca/200301/noticias/pagina3 070103.htm

García-Pablos de Molina, Antonio (1984), La supuesta función resocializadora del Derecho penal, en Estudios Penales, Bosch, Barcelona, pp. 17-96.

Hassemer, Winfried (1984), Fundamentos del Derecho penal, Bosch, Barcelona.

Hassemer, Winfried y Muñoz Conde, Francisco (1989), Introducción a la Criminología $y$ al Derecho penal, Tirant lo Blanch, Valencia.

Hassemer, Wienfried y Muñoz Conde, Francisco (2001), Introducción a la Criminología, Tirant lo Blanch, Valencia.

Jakobs, Günther (1999), La ciencia del Derecho penal frente a las exigencias del presente, en Estudios de Derecho Judicial 20, pp. 137 y ss.

Larrauri, Elena (1998), Introducción para el lector español a la obra de v.Hirsch, Censurar y castigar, Trotta, Madrid.

Manzanares Samaniego, José Luis (2003), El cumplimiento íntegro de las penas, Actualidad Penal 2003-1, pp. 195-214.

Martinson, Robert (1974), What works? Questions and answers about prison reform, The Public Interest 35, pp. 22-54.

Muñoz Conde, Francisco (1980), La resocialización del delincuente, análisis y crítica de un mito, en Mir Puig (edit.), La reforma del Derecho penal, Universidad Autónoma de Barcelona, Bellaterra, pp. 61-81 (publicado también en Cuadernos de Política Criminal 7, 1979, pp. 91 y ss.).

Muñoz Conde, Francisco (2003a), ¿Hacia un Derecho penal del enemigo?, artículo de prensa publicado en El País de 15 de enero. 
Muñoz Conde, Francisco (2003b), Edmund Mezger y el Derecho penal de su tiempo (4 ${ }^{\mathrm{a}}$ ed.), Tirant lo Blanch, Valencia.

Muñoz Conde, Francisco, y García Arán, Mercedes (2002), Derecho penal, Parte General ( $5^{\mathrm{a}}$ ed.), Tirant lo Blanch, Valencia.

Redondo Illescas, Santiago (1997), Intervenciones con delincuentes, reinserción y reincidencia, en Varios, La Criminología aplicada, Cuadernos de Derecho Judicial, Consejo General del Poder Judicial, Madrid, pp. 149-175.

Renart García, Felipe (2003), La libertad condicional: nuevo régimen jurídico, Edisofer, Madrid.

Requejo Conde, Carmen (2000), Ámbito y aplicación del art. 78 CP, Actualidad Penal 26, pp. 549-559.

Silva Sánchez, Jesús M (2001), El retorno de la inocuización. El caso de las reacciones jurídico-penales frente a los delincuentes sexuales violentos, en Arroyo Zapatero/ Berdugo Gómez de la Torre (dir.), Homenaje al Dr. Marino Barbero Santos, In memoriam, Cuenca, pp. 699-710.

Téllez Aguilera, Abel (2003), La Ley de cumplimiento íntegro y efectivo de las penas: una nota de urgencia, El Derecho penitenciario, http://geo.ya.com/webprisiones/opinion/15.htm

Von Hirsch, Andrew (1998), Censurar y castigar, Trotta, Madrid (traducido por Larrauri).

Von Liszt, (1905), Der Zweckgedanke im Strafrecht, en Strafrechtliche Vorträge und Aufsätze I, Berlin.

Carmen López Peregrín es doctora en Derecho por la Universidad de Sevilla. Actualmente desarrolla líneas de investigación en delitos de peligro y fines de la pena. En el año 2001 obtuvo una Beca de Investigación de la Fundación Alexander von Humboldt. Entre sus publicaciones se encuentran las monografias "La complicidad en el delito" y "La protección penal del honor de las personas jurídicas y los colectivos". En la actualidad es Profesora Titular de Derecho penal en la Universidad Pablo de Olavide de Sevilla y Coordinadora del Programa de Doctorado "Problemas actuales del Derecho penal y la Criminología" en dicha Universidad.

iD https://orcid.org/0000-0002-4063-5380

Revista Española de Investigación Criminólogica

REIC AC-02-03

http://www.criminologia.net

ISSN 1696-9219

https://doi.org/10.46381/reic.v1i0.6 